\title{
Total factor productivity efficiency changes in a Malaysian hotel chain
}

\begin{abstract}
This paper investigates the changes in total factor productivity (TFP) of a Malaysian hotel chain during the period of 2002-2008. TFP change is measured by Malmquist index, using data envelopment analysis (DEA) approach. The data were collected from eight hotels under the chain. Overall, the results revealed that the TFP of the hotel chain has slightly increased by $0.8 \%$ over the time period. Within the chain, four of the hotels experienced positive TFP change while the others experienced TFP decline. The hotels were segregated into quadrant of efficiency which give a two dimensional view of the hotel efficiency. Technological change is found to be more important factor of TFP growth as compared to technical efficiency change. As such, it is recommended that hotels which experienced negative growths of technological change improve their efficiency through investment in new technology or upgrading the necessary skills.
\end{abstract}

Keyword: Data envelopment analysis; DEA; Hotel efficiency; Malaysian hotel chain; Malmquist index; TFP; Total factor productivity 